\title{
Envelhecimento populacional, gratuidades no transporte público e seus efeitos sobre as tarifas na Região Metropolitana de São Paulo
}

\author{
Rafael Hen rique Moraes Pereira* \\ Carlos Henrique Ribeiro de Carvalho** \\ Pedro Herculano G. Ferreira de Souza ${ }^{\star \star \star}$ \\ Ana Amelia Camarano ${ }^{\star \star \star \star}$
}

No Brasil, estudantes, crianças de até quatro anos de idade e idosos com 65 anos ou mais têm direito a descontos parciais ou totais em viagens urbanas nos sistemas de transporte público. Esses descontos não são cobertos por fundos públicos, mas sim por subsídio cruzado cobrado dos demais usuários que pagam a tarifa cheia. Neste estudo, são estimados os efeitos do envelhecimento populacional sobre o preço das passagens do transporte público nas próximas quatro décadas na Região Metropolitana de São de Paulo (RMSP), a maior região metropolitana do país. As análises são baseadas nos dados da Pesquisa Origem-Destino, realizada em 2007 na RMSP, e nas projeções demográficas elaboradas pelo IBGE e pela Fundação Seade para 2020, 2030 e 2050. Considerando os diferentes períodos de projeção populacional, adaptou-se a técnica de padronização direta para simular as mudanças esperadas na composição das viagens do sistema de transporte, em termos de passageiros pagantes e não pagantes. Os resultados indicam que, no curto prazo (2020), o envelhecimento populacional estimado para ocorrer na RMSP teria efeito modesto sobre o número total e a composição etária das viagens realizadas no transporte público da região. No médio e longo prazos, contudo, o crescimento previsto na proporção de passageiros com gratuidades poderia ocasionar aumento no sobrepreço da tarifa, com elevação de seu valor em cerca de $10 \%$ e de $20 \%$, caso seja mantido o mecanismo de subsídios cruzados.

Palavras-chave: Envelhecimento demográfico. Transporte público. Transporte urbano. Tarifa. Gratuidades. Região Metropolitana de São Paulo.

\footnotetext{
* Transport Studies Unit, School of Geography and the Environment, University of Oxford, UK. e Instituto de Pesquisa Econômica Aplicada - Ipea, Brasília-DF, Brasil (rafael.pereira@ipea.gov.br).

** Instituto de Pesquisa Econômica Aplicada - Ipea, Brasília-DF, Brasil (carlos.carvalho@ipea.gov.br).

*** University of California, Economics Department, Berkeley, USA ( pedrosouza@gmail.com).

${ }^{\star \star \star \star}$ Instituto de Pesquisa Econômica Aplicada - Ipea, Rio de Janeiro-RJ, Brasil (ana.camarano@ipea.gov.br).
} 


\section{Introdução}

A revisão recente das projeções populacionais do Brasil feitas pelo IBGE (2013) reforça a preocupação de demógrafos quanto aos desafios que o país enfrentará nas próximas décadas, devido ao seu acelerado processo de envelhecimento populacional. A literatura demográfica nacional tem se concentrado, particularmente, em discutir questões que deverão ser enfrentadas nas áreas de saúde, seguridade social, cuidados e mercado de trabalho (CAMARANO, 2004; WONG; CARVALHO, 2006; BERENSTEIN; WAJNMAN, 2008; CAMARANO; KANSO, 2011).

Pouca atenção, no entanto, está sendo dada aos desafios que o envelhecimento populacional deverá acarretar para as questões de transporte urbano no país. No caso brasileiro, em particular, merece destaque a existência de um quadro normativo-legal que define como direito fundamental da população de 65 anos e mais de idade o acesso gratuito aos serviços de transporte coletivo urbano. Esse direito passou a ter validade em todo o território nacional a partir da Constituição Federal de 1988 e foi posteriormente ratificado em lei federal pelo Estatuto do Idoso (ANTP, 2005; BRASIL, 2003, 2008). ${ }^{1}$

Via de regra, tanto a isenção para os idosos quanto outros descontos usufruídos por outros grupos sociais (estudantes, carteiros, policiais, pessoas com deficiência, etc.) são financiados por subsídios cruzados. Isso significa que o custo de suas viagens é incorporado ao valor final da tarifa paga pelos demais usuários do sistema de transporte público. A consequência mais imediata desse modelo de financiamento são tarifas mais caras (ANTP, 2005; CARVALHO; PEREIRA, 2012; CARVALHO et al., 2013). Indiretamente, esse encarecimento tende a reduzir o número de pessoas que estariam dispostas a utilizar o transporte público pelo preço mais alto cobrado (GOMIDE, 2003). Estas seriam pessoas não idosas, que estariam financiando o transporte das idosas, reforçando os estudos de transferências intergeracionais que apontam que estas constituem a principal fonte de consumo de idosos e crianças.

Turra, Queiroz e Rios-Neto (2011) chamam a atenção para as idiossincrasias das transferências intergeracionais no Brasil, referentes às maiores transferências intergeracionais públicas feitas para idosos em comparação às das crianças. Mas, enquanto as transferências públicas são financiadas principalmente pela população trabalhadora como um todo, no sistema de financiamento do transporte público com subsídios cruzados essas transferências são feitas exclusivamente pelos passageiros pagantes do transporte público, que são predominantemente de baixa renda (GOMIDE, 2003; CARVALHO et al., 2013).

Nesse contexto, o objetivo do presente estudo é estimar qual será o efeito do envelhecimento populacional sobre o perfil etário dos usuários de um sistema de transporte público no Brasil e o seu desdobramento sobre o valor cobrado nas tarifas. Considerando

\footnotetext{
${ }^{1}$ Diversos municípios já haviam definido a gratuidade no transporte coletivo urbano para sua população idosa antes da Constituição Federal de 1988, como apontam Camarano e Pasinato (2004). Esse é o caso, por exemplo, dos municípios de São Paulo (Lei 9.651/83) e de Aracaju (Decreto 59-83).
} 
diferentes anos de projeção populacional (2020, 2030 e 2050), adaptou-se a técnica de padronização direta para simular as mudanças esperadas na composição das viagens do sistema de transporte, em termos de passageiros pagantes e não pagantes. Assim, foi possível estimar também o aumento do peso que os subsídios cruzados teriam sobre o preço final das passagens diante dos possíveis cenários projetados de envelhecimento populacional.

As análises desse trabalho tomaram a Região Metropolitana de São Paulo (RMSP) como estudo de caso, por se tratar da maior região metropolitana brasileira e para a qual há boa disponibilidade de dados detalhados sobre transporte urbano e projeções demográficas. Foram utilizados dados da Pesquisa Origem-Destino (OD) realizada em 2007 na RMSP (METRÔ, 2008), além dos resultados de projeções demográficas oficiais elaboradas pela Fundação Sistema Estadual de Análise de Dados (Seade) do Estado de São Paulo e pelo IBGE (2013).

A seguir discorre-se sobre a noção de envelhecimento a partir da ótica demográfica. Posteriormente apresentam-se a metodologia utilizada neste estudo e os resultados encontrados. Por fim são feitas algumas considerações finais.

\section{Abordagens sobre envelhecimento populacional na literatura de transporte e demográfica}

Embora haja uma vasta bibliografia nacional e internacional sobre envelhecimento e transporte urbano, essa literatura se foca fundamentalmente na questão do envelhecimento individual, relacionado à extensão da longevidade das pessoas. Em larga medida, os estudos se debruçam sobre como a idade avançada das pessoas molda suas experiências individuais de mobilidade urbana em termos de frequência de deslocamentos, modos de transportes e dificuldades de locomoção nos seus deslocamentos diários (METZ, 2003; MERCADO et al., 2007; PAEZ et al., 2007; MARANDOLA JR.; HOGAN, 2008; SCHWANEN; PAEZ, 2010; WASFI et al., 2012). Tais trabalhos apontam que, em média, a população idosa tende a realizar um menor número de viagens por dia, com menos atividade no período noturno e fora dos horários de pico, percorrendo menores distâncias e usando menos o automóvel do que pessoas mais jovens. Como destacam os autores, essas diferenças refletem, em larga medida, o efeito da aposentadoria e das dificuldades de locomoção acarretadas pelo avançar da idade sobre as mudanças no estilo de vida e na participação de atividades extradomiciliares. Roberts e Babinard (2004) também indicam que diversas iniciativas do Banco Mundial de apoio às políticas de transporte urbano em países em desenvolvimento têm se focado sobre as questões de promoção de acessibilidade para idosos e pessoas com alguma deficiência.

No Brasil, alguns estudos têm discutido os desafios que o envelhecimento populacional coloca em termos de segurança no trânsito, para as necessidades de adequação da frota de transporte público e do mobiliário urbano, visando melhorar as condições de acessibilidade das cidades para populações idosa e portadora de deficiência (SANT’ANNA et al., 2003, 
2004; OLIVEIRA et al., 2012). A importância que essa questão assume na agenda pública nacional também fica evidenciada pelo conjunto de leis e decretos que tratam do assunto estabelecendo normas gerais e critérios básicos de acessibilidade, como a Política Nacional do Idoso (Decreto n. 1.948/1996), o Estatuto das Pessoas com Deficiência (Decreto n. 3.298/1999), a Lei de Acessibilidade (Lei n. 10.098/2000) e o Estatuto do Idoso (Lei n. 10.741/2003).

Contudo, em contraste com esta literatura que aborda o envelhecimento do ponto de vista do ciclo de vida do indivíduo que chega a idades avançadas, pouca atenção tem sido dada à questão mais ampla do envelhecimento populacional e aos efeitos econômicos que este processo deverá exercer sobre os serviços de transporte público urbano no país. 0 envelhecimento populacional é a mudança no peso relativo que cada grupo etário assume no conjunto da população, com a redução da proporção de pessoas em idades jovens e aumento nas idades mais avançadas. No caso brasileiro, o envelhecimento populacional vem ocorrendo em ritmo acelerado quando comparado a outros países (WONG; CARVALHO, 2006). Esse processo decorre, primeiramente, da acelerada queda das taxas de fecundidade (envelhecimento pela base), que foi seguida por um envelhecimento pelo topo, isto é, pela redução dos níveis de mortalidade nas idades mais avançadas (CAMARANO; KANSO, 2009).

O Gráfico 1 mostra como as estruturas etárias da população do Brasil e da RMSP vêm se modificando desde a década de 1980 , bem como a participação dos grandes grupos etários estimada até 2050, segundo as projeções oficiais da Fundação Seade (2012) e do IBGE (2013). Apesar de a RM de São Paulo ser umas das aglomerações urbanas mais ricas do país e uma das regiões onde mais cedo se observou o declínio de suas taxas de fecundidade (POTTER et al., 2010), o ritmo de envelhecimento projetado para a RMSP nas próximas duas décadas se assemelha muito à projeção estimada para o total do Brasil.

GRÁFICO 1

Distribuição da população, segundo grandes grupos etários

Região Metropolitana de São Paulo e Brasil - 1980-2050

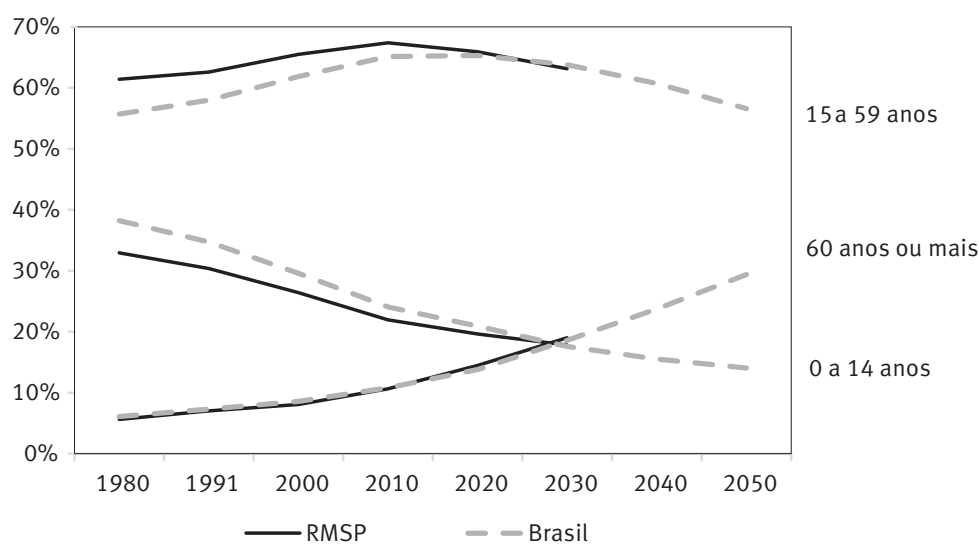

Fonte: Censos Demográficos 1980, 1991, 2000 e 2010 (IBGE); Projeção Demográfica do Brasil (IBGE, 2013); Projeção Demográfica de São Paulo (FUNDAÇÃO SEADE, 2012). 
É razoável esperar que a alteração na composição etária da população como um todo deverá ter desdobramentos na composição etária das viagens realizadas dentro do sistema de transporte público. Um deles seria o padrão de viagens observado entre pessoas de idade mais avançada; uma região metropolitana mais envelhecida poderá significar menos viagens.

Tendo em vista que a concessão de benefícios tarifários no Brasil possui forte vinculação com o perfil etário dos usuários de transporte coletivo (crianças, estudantes e idosos), parece importante investigar que efeitos essa alteração demográfica poderá ter sobre a composição das viagens no transporte público. Como as mudanças na proporção de viagens pagantes e não pagantes poderá afetar o preço cobrado das tarifas? 0 aumento da população idosa, por exemplo, poderia ser compensado pela diminuição da população jovem estudante?

\section{Metodologia}

Em linhas gerais, o total de viagens realizadas diariamente no sistema de transporte público de uma região metropolitana é resultado da combinação entre o tamanho total da população residente, a estrutura etária dessa população e o número médio de viagens realizadas por dia pela população em cada faixa etária no transporte público (ou seja, o índice de mobilidade específico por idade no transporte público). A diferença que deverá ser observada entre a composição etária e o total de viagens na RMSP registradas em determinado ano e as viagens que deverão ocorrer num momento futuro (por exemplo, em 2020) é uma função das mudanças que ocorrerão nessas três variáveis dentro desse horizonte temporal. No presente estudo, pretende-se estimar qual parcela dessa diferença deverá decorrer, exclusivamente, de uma alteração da estrutura etária da população, isolando-se o efeito do envelhecimento populacional. Para isso, foram utilizados os dados da pesquisa Origem-Destino (OD) realizada na RMSP, em 2007. A coleta de dados da OD foi feita entre agosto e novembro de 2007, com base numa amostra domiciliar representativa de todos os deslocamentos realizados num típico dia útil na Região Metropolitana de São Paulo, durante esse período. Pesquisas Origem/Destino (ODs) são tradicionalmente as fontes de dados mais completas sobre transporte urbano no Brasil e permitem estimar, entre outras coisas, o número de viagens realizadas pela população segundo sexo, idade e modo de transporte utilizado.

A partir dos dados da pesquisa OD, foi possível fazer um exercício de simulação em duas etapas, de modo semelhante a análises de padronização direta aplicadas por Wong e Carvalho (2006) e por Berenstein e Wajman (2008). A primeira etapa consistiu em estimar: a proporção de usuários pagantes e não pagantes no total de viagens no sistema de transporte público; o peso das gratuidades sobre o valor das tarifas pagas; e a receita tarifária arrecadada, assumindo-se um custo médio por viagem constante de $\mathrm{R} \$ 1,00$.

Na segunda etapa, esses mesmos indicadores foram calculados assumindo-se que a população da RMSP em 2007 tivesse a estrutura etária prevista para a região em 2020 e 2030. 
Adicionalmente, incluiu-se na análise um cenário assumindo a estrutura etária projetada para o Brasil em 2050. Os resultados foram então comparados com os valores obtidos na primeira etapa. Dessa forma, tomaram-se como base nesses cálculos o tamanho total da população em 2007, padronizado pelas estruturas etárias em 2020, 2030 e 2050, e os índices de mobilidade específicos por idade no transporte público (IME) observados em 2007.

0 presente estudo faz uma adaptação da técnica de padronização direta. Da maneira como tradicionalmente realizada em trabalhos demográficos, a padronização direta utiliza a estrutura etária de uma população como padrão de referência para comparar a incidência de um fenômeno de interesse em populações com diferentes estruturas etárias. Isso permite anular os efeitos que suas respectivas estruturas etárias possuem no cômputo das suas taxas brutas, possibilitando, assim, comparar a incidência pura desse fenômeno nas populações de interesse (CARVALHO et al., 1998). Este estudo, por sua vez, constrói simulações contrafactuais que mantêm constantes tanto o tamanho da população da RMSP quanto os seus índices de mobilidade específicos por idade, e verifica como as estruturas etárias diferentes projetadas para essa população ao longo do tempo deverão afetar a composição etária dos passageiros no seu sistema de transporte. Como as gratuidades no transporte público estão atreladas ao perfil de idade dos passageiros, essas simulações permitem estimar o efeito puro do envelhecimento populacional sobre o preço das passagens em um sistema de subsídios cruzados.

Diante das dificuldades tanto em simular possíveis mudanças nos índices de mobilidade quanto em prever eventuais transformações geradas por aumentos de escala ligados ao tamanho da população, tal procedimento parece ser o mais razoável, permitindo avaliar, ceteris paribus, o impacto puro do envelhecimento populacional sobre o número médio de viagens, bem como o peso dos benefícios tarifários sobre o valor da tarifa cobrada.

A seguir são apresentados de maneira mais detalhada os procedimentos metodológicos utilizados para decomposição do índice de mobilidade e da receita tarifária. Também é feita uma explicação sumária acerca da técnica de padronização direta utilizada.

\section{Decomposição do índice de mobilidade bruta}

0 índice de mobilidade é um indicador tradicionalmente utilizado em estudos na área de transportes e expressa o número de viagens que uma pessoa faz em média por dia (VASCONCELLOS, 2001). Sua fórmula de cálculo mais direta é a razão entre o número total de viagens realizadas em determinada região num típico dia útil e o tamanho total da população residente. No presente estudo, esse índice será denominado de índice de mobilidade bruto (IMB), por ser calculado para o total da população, desconsiderando sua distribuição etária:

$I M B=\frac{\sum_{i=1}^{n} v_{i}}{n}=\frac{V}{n}$ 
Onde:

$I M B$ : índice de mobilidade bruto;

$\mathrm{v}_{i}$ : número total de viagens do indivíduo $i$;

$V$ : número total de viagens;

$n$ : população residente total.

Para uma análise que incorpore a composição etária da população no seu índice de mobilidade, é possível construir o índice de mobilidade específico por idade (IME) ao desagregar os dados para cada faixa etária $j$ e expressar o IMB como a soma ponderada dos IMEs:

$I M E_{j}=\frac{\sum_{i=1}^{n_{j}} v_{i j}}{n_{j}}=\frac{V_{j}}{n_{j}}$

$I M B=\frac{\sum_{j=1}^{J}\left(I M E_{j} n_{j}\right)}{n}=\frac{\sum_{j=1}^{J} V_{j}}{n}$

Onde:

$I M E_{j}$ : índice de mobilidade específico por idade para a faixa etária $j ;$

$V_{j}$ : número total de viagens realizadas pela população pertencente à faixa etária $j$;

$n_{j}$ : população residente pertencente à faixa etária $j$;

$n$ : população residente total.

A partir dos dados da Pesquisa Origem-Destino realizada em 2007 na RMSP, é possível calcular o índice de mobilidade específico por idade (IME) para cada modo de transporte (i.e., o número médio de viagens que uma pessoa em cada grupo etário realiza por dia em cada modo de transporte). No caso do presente estudo, será calculado o índice de mobilidade específico por idade no transporte público, considerando-se apenas as viagens realizadas por metrô, trem, ônibus, lotação, micro-ônibus ou vans.

Para o cálculo dos índices de mobilidade, considerou-se no denominador a população residente na região metropolitana, porque a pesquisa OD entrevista apenas domicílios dentro do perímetro metropolitano. Isso não permite estimar o número de pessoas residentes fora da região metropolitana que realizam viagens dentro do sistema de transporte público da região. ${ }^{2}$

\section{Simulações}

A comparação entre os índices de mobilidade brutos de duas áreas (ou de uma mesma área em momentos distintos) pode ser enviesada, uma vez que o número total de viagens

\footnotetext{
$\overline{2}$ Dado o tamanho da RMSP, espera-se que esse número seja relativamente pequeno em relação ao total de viagens realizadas no sistema. Além disso, não haveria razão para supor que esses usuários externos possuam um perfil etário extremamente diferente daqueles residentes na RMSP. De qualquer maneira, esse pressuposto foi adotado apenas para fins práticos neste estudo e sua adoção pode não ser válida para a análise de municípios específicos com altas taxas de pendularidade.
} 
observado em uma população é dependente de sua estrutura etária. Uma maneira de eliminar o efeito da composição etária sobre indicadores brutos é recorrendo-se à técnica de padronização direta, que permite isolar o efeito que a estrutura etária possui sobre esse tipo de indicador (CARVALHO et al., 1998; PRESTON et al., 2001).

Nas simulações realizadas no presente estudo, adaptou-se esta técnica de padronização direta aplicando as taxas de mobilidade específicas por idade obtidas a partir da OD de 2007 à população total residente na RMSP em 2007, considerando-se que ela assumiria quatro distribuições etárias distintas: a própria estrutura observada em 2007; as estruturas etárias estimadas para a RMSP em 2020 e 2030; e a estrutura projetada para o Brasil em 2050. Ou seja, apenas o $n_{j}$ das equações (2) e (3) varia.

Como apontado por Carvalho et al. (1998, p. 44), essa simulação assume como pressuposto que a estrutura etária das taxas de mobilidade seja constante. Isso quer dizer que não importa se o índice bruto de mobilidade em 2020 será maior ou menor do que em 2007, desde que a distribuição relativa dessas taxas em cada faixa etária siga uma constante $k$. Assim, esse teste permite neutralizar o efeito que poderia advir de variações do número total de viagens no transporte público. Com isso, torna-se possível captar as mudanças de composição e quantidade de viagens pagantes que decorreriam exclusivamente do envelhecimento populacional que se observará na região.

\section{Entendendo a tarifa e a receita tarifária do transporte público}

Via de regra, os custos do transporte público por ônibus no Brasil são cobertos exclusivamente pela arrecadação tarifária. ${ }^{3}$ Nesses sistemas, a tarifa de equilíbrio deve ter um valor no qual a receita total do sistema se iguale ao seu custo total para que o equilíbrio financeiro do sistema seja alcançado. ${ }^{4}$

$$
\begin{aligned}
& C T=R T \\
& R T=T \times P P \\
& C T=T \times P P \Rightarrow T=\frac{C T}{P P}
\end{aligned}
$$

Onde:

CT: custo total do sistema;

$R T$ : receita total do sistema;

$T$ : tarifa cobrada dos usuários para equilibrar financeiramente o sistema;

$P P$ : passageiros pagantes equivalentes do sistema, ou viagens pagantes equivalentes do sistema.

\footnotetext{
$\overline{3}$ Entre as exceções que recebem subsídios estatais está a cidade de São Paulo, que cobre atualmente cerca de $20 \%$ do custo do sistema com recursos orçamentários da prefeitura. Essa proporção varia mês a mês, de acordo com os relatórios de despesas e receitas divulgados pela SPtrans no seu site (www.sptrans.com.br).

${ }^{4}$ Todos os custos relacionados à operação dos sistemas são considerados no cálculo do custo total, incluindo aí depreciação e impostos, além da remuneração do capital empregado pelos operadores. Para uma revisão da tarifação do transporte público no Brasil, ver os estudos de Lima (1992), Gomide (2004) e Carvalho et al. (2013).
} 
A partir da condição de igualdade entre receita e custo, a tarifa de um sistema é calculada pelo rateio do custo total do sistema de transportes pelo número de viagens pagantes equivalentes (VP). ${ }^{5}$ Isso significa que o valor da tarifa de equilíbrio do sistema será maior quanto maior for a proporção de passageiros isentos e, consequentemente, menor a proporção de passageiros pagantes.

A equação (4) pode ser desmembrada, ainda, de maneira a diferenciar os usuários que efetivamente pagam o valor cheio da tarifa e aqueles que recebem benefícios tarifários segundo o valor do benefício recebido. Para categorias de usuários, em que cada categoria recebe um desconto ou benefício tarifário $0 \leq D_{k} \leq 1$, temos:

$R T=T \times \sum_{k=1}^{K}\left(1-D_{k}\right) \times V_{k}$

Onde:

$R T$ : receita tarifária;

T: valor cheio da tarifa cobrada;

$D_{k}$ : desconto da tarifa (em proporção da tarifa cheia) para passageiros da categoria $k$ de desconto;

$V_{k}$ : número de viagens realizadas por passageiros em cada categoria $k$ de desconto.

$\mathrm{Na}$ prática, existem diversos grupos que recebem benefício tarifário (parcial ou total), dos quais se destacam crianças, idosos, estudantes, oficiais de justiça, carteiros, população indígena, guardas metropolitanos, policiais civis e militares fardados, pessoas com deficiência, entre outros. A definição de quais grupos recebem o benefício e qual o tamanho deste é feita por legislação específica de cada município, o que resulta na existência de grande heterogeneidade de grupos beneficiários em cada cidade, mesmo entre aqueles municípios pertencentes a uma mesma região metropolitana. A gratuidade para população acima de 65 anos de idade é o único benefício válido em todo o território nacional garantido pela Constituição Federal de 1988.

Tendo em vista que o foco deste estudo são os benefícios tarifários diretamente relacionados às transformações demográficas em curso, optou-se por simplificar o trabalho de forma a considerar apenas três tipos de usuários: usuários com o desconto integral (gratuidade) nas viagens, incluindo-se aqui crianças com até cinco anos de idade e idosos com 65 ou mais anos de idade; usuários com desconto parcial (de 50\%), abarcando as viagens feitas por pessoas em fase escolar entre 5 e 14 anos de idade; e usuários que pagam o valor cheio da tarifa sem desconto algum. Em nome da simplicidade, assumiu-se que todas as viagens realizadas nos modos de transporte público coletivo da RMSP são feitas por usuários que se enquadram em um desses três grupos.

Partindo do pressuposto de que a estrutura da rede de transporte ofertada não seria alterada em função do envelhecimento populacional, considera-se então como premissa

\footnotetext{
${ }_{5}^{5}$ No caso do transporte público, os termos passageiros pagantes equivalentes ou viagens pagantes equivalentes são uma forma de contabilizar o número de passageiros ou viagens pagas considerando-se os descontos tarifários recebidos pelas diferentes categorias de beneficiários. Dessa forma, duas viagens de estudantes com desconto de $50 \%$ equivalem a uma viagem integral, ou seja, um passageiro pagante equivalente.
} 
que o custo total do sistema não seria alterado, o que equivaleria a manter a mesma rede de transporte público. ${ }^{6} 0$ custo médio de $R \$ 1,00$ escolhido para o ano inicial dos cálculos (2007) é puramente hipotético, servindo apenas para facilitar a interpretação dos resultados. ${ }^{7}$ Como se opera com o pressuposto de que o custo total deve ser equivalente à receita total, isso implica adotar tarifas que mantenham o equilíbrio do sistema ao fazer com que a arrecadação total seja equivalente ao custo inicial considerado.

\section{Resultados}

De acordo com os dados da pesquisa OD, em 2007 foram realizadas diariamente cerca de 11.896 viagens internas à região utilizando o transporte público coletivo como modo principal de viagem. Considerando-se que a estimativa da população residente na RMSP estava em torno de 19,5 milhões de pessoas, o IMB no transporte público em 2007 foi de 0,61 . Isso significa que uma pessoa residente na RMSP fazia uma média de 0,61 viagem por dia no sistema de transporte público. Como apontado anteriormente, a intensidade de utilização do transporte público varia conforme a idade das pessoas. Isso pode ser visualizado pelo Gráfico 2, que apresenta o índice de mobilidade específico por idade no transporte público (IME).

\section{GRÁFICO 2}

Índice de mobilidade específico no transporte público (1), por faixa etária Região Metropolitana de São Paulo - 2007

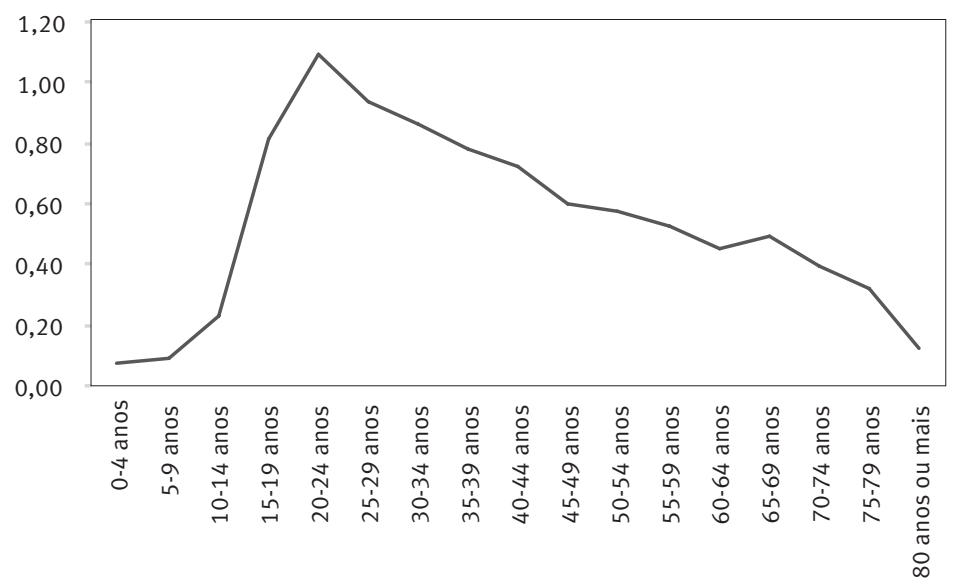

Fonte: Microdados da Pesquisa OD 2007 (Metrô).

(1) Inclui metrô, trem, ônibus, lotação, micro-ônibus e vans.

\footnotetext{
$\overline{6}$ Pode-se argumentar que a oferta de transporte ajustar-se-ia no longo prazo à variação negativa da demanda, o que quebraria essa condição de custo total constante. Mas, além de se constituir uma premissa importante no processo de isolamento do efeito do envelhecimento, pode-se contra-argumentar que a redução da demanda nem sempre acarreta movimentos de redução de oferta, em função das fortes pressões sociais que os gestores sofrem nesse processo.

${ }^{7} \mathrm{O}$ valor absoluto do custo médio não interfere nos cálculos finais relativos dos impactos gerados. Optou-se pelo valor unitário para facilitar o entendimento dos cálculos.
} 
A partir das informações do Gráfico 2, podem ser destacadas ao menos três características marcantes dos usuários do sistema público de transporte. Primeiro, crianças entre 0 e 14 anos de idade fazem um número muito pequeno de viagens por dia. Segundo, é no grupo etário de 15 a 54 anos que se observa maior utilização do transporte público, com um pico entre 20 e 24 anos. De certa maneira, tais resultados já eram esperados, uma vez que esses dois períodos do ciclo de vida de uma pessoa estão marcados, respectivamente, por uma baixa autonomia e por uma maior inserção em atividades de estudo e no mercado de trabalho, como já apontado por pesquisas anteriores (VASCONCELLOS, 2001; PAEZ et al., 2007; MARANDOLA JR.; HOGAN, 2008; SCHWANEN; PAEZ, 2010; WASFI et al., 2012).

Um terceiro ponto a ser destacado é que, depois do pico de mobilidade na faixa entre 20 e 24 anos, observa-se uma queda contínua do IME que é interrompida somente na passagem da faixa de 60-64 para 65-69 anos. Esse "soluço" aponta claro aumento do uso do transporte público a partir desse grupo etário e que, ao que tudo indica, estaria relacionado à gratuidade no transporte público concedido para a população a partir dos 65 anos de idade. Uma vez que a utilização desses serviços se torna gratuita a partir dessa idade, é de se esperar uma ampliação no número de viagens, particularmente daqueles idosos que não tinham condições de renda para pagar o valor da tarifa, ou daqueles que até tinham alguma condição financeira, mas não estavam dispostos a pagar o preço cobrado pelo serviço.

Outra característica a ser analisada nas viagens realizadas no sistema de transporte público da RMSP é o seu perfil demográfico (Gráfico 3), que apresentava, em 2007, uma estrutura etária relativamente jovem em comparação à população total residente na região. Mais de $50 \%$ das viagens foram feitas por pessoas de 15 a 34 anos, contra $7 \%$ para o grupo de crianças com menos de cinco anos e idosos e menos de $4 \%$ para estudantes de 5 a 14 anos.

A Tabela 1 apresenta a estrutura etária da população da RMSP em 2007 e as projeções para essa região em 2020 e 2030 e para o Brasil em 2050. A mudança na estrutura etária deverá ocorrer de forma gradual. Até 2020, será observada pequena queda na participação relativa da população de 10 a 29 anos de idade. Em relação a 2007, a projeção para a RMSP em 2030 prevê uma redução mais acentuada da população jovem (entre 5 e 29 anos) e um aumento mais expressivo da população acima de 60 anos de idade. A comparação com a projeção nacional para 2050 é ainda mais contrastante, com um quadro de envelhecimento populacional mais acentuado. 


\section{GRÁFICO 3}

Distribuição das viagens realizadas no sistema de transporte público coletivo (1) e da população residente, por sexo, segundo faixas etárias

Região Metropolitana de São Paulo - 2007

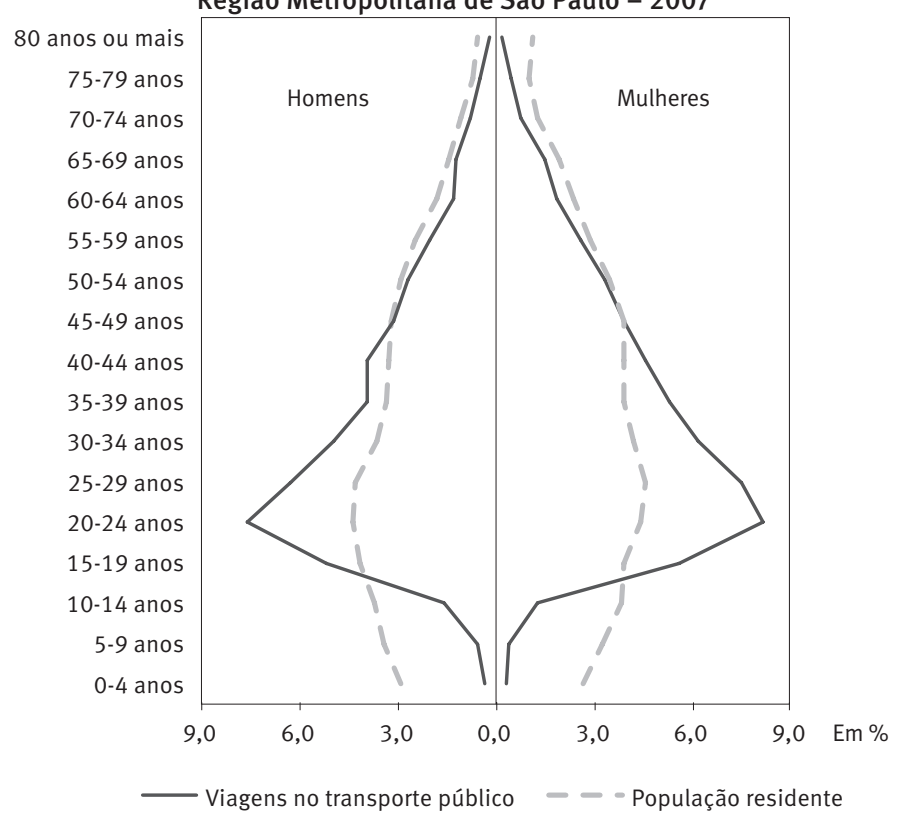

Fonte: Microdados da Pesquisa OD 2007 (Metrô).

(1) Inclui metrô, trem, ônibus, lotação, micro-ônibus e vans.

TABELA 1

Distribuição da população e projeções, segundo faixas etárias Região Metropolitana de São Paulo e Brasil - 2007-2050

\begin{tabular}{|c|c|c|c|c|c|c|c|c|c|c|c|}
\hline \multirow{3}{*}{ Faixas etárias } & \multicolumn{6}{|c|}{ RMSP } & \multirow{2}{*}{\multicolumn{2}{|c|}{$\begin{array}{l}\text { Brasil } \\
2050\end{array}$}} & \multirow{2}{*}{\multicolumn{3}{|c|}{$\begin{array}{c}\text { População de } 2007 \\
\text { (em mil) padronizada } \\
\text { segundo a estrutura } \\
\text { etária }\end{array}$}} \\
\hline & \multicolumn{2}{|c|}{2007} & \multicolumn{2}{|c|}{2020} & \multicolumn{2}{|c|}{2030} & & & & & \\
\hline & $\begin{array}{c}\text { População } \\
\text { (em mil) }\end{array}$ & $\%$ & $\begin{array}{c}\text { População } \\
\text { (em mil) }\end{array}$ & $\%$ & $\begin{array}{c}\text { População } \\
\text { (em mil) }\end{array}$ & $\%$ & $\begin{array}{c}\text { População } \\
\text { (em mil) }\end{array}$ & $\%$ & 2020 & 2030 & 2050 \\
\hline $0-4$ anos & 1.081 & 5,5 & 1.417 & 6,7 & 1.242 & 5,6 & 9.992 & 4,4 & 1.310 & 1.096 & 862 \\
\hline 5-9 anos & 1.301 & 6,7 & 1.461 & 6,9 & 1.314 & 5,9 & 10.611 & 4,7 & 1.350 & 1.159 & 916 \\
\hline 10-14 anos & 1.475 & 7,6 & 1.271 & 6,0 & 1.391 & 6,3 & 11.246 & 5,0 & 1.175 & 1.227 & 971 \\
\hline 15-19 anos & 1.573 & 8,0 & 1.396 & 6,6 & 1.467 & 6,6 & 11.781 & 5,2 & 1.290 & 1.294 & 1.017 \\
\hline 20-24 anos & 1.716 & 8,8 & 1.677 & 7,9 & 1.343 & 6,1 & 12.290 & 5,4 & 1.550 & 1.185 & 1.061 \\
\hline 25-29 anos & 1.744 & 8,9 & 1.632 & 7,7 & 1.484 & 6,7 & 12.910 & 5,7 & 1.508 & 1.309 & 1.114 \\
\hline 30-34 anos & 1.537 & 7,9 & 1.759 & 8,3 & 1.698 & 7,7 & 13.587 & 6,0 & 1.625 & 1.498 & 1.173 \\
\hline 35-39 anos & 1.416 & 7,3 & 1.801 & 8,5 & 1.595 & 7,2 & 14.359 & 6,3 & 1.664 & 1.407 & 1.239 \\
\hline 40-44 anos & 1.407 & 7,2 & 1.672 & 7,9 & 1.700 & 7,7 & 15.258 & 6,7 & 1.545 & 1.499 & 1.317 \\
\hline 45-49 anos & 1.392 & 7,1 & 1.473 & 7,0 & 1.729 & 7,8 & 16.128 & 7,1 & 1.361 & 1.525 & 1.392 \\
\hline 50-54 anos & 1.254 & 6,4 & 1.339 & 6,3 & 1.590 & 7,2 & 16.089 & 7,1 & 1.237 & 1.402 & 1.389 \\
\hline 55-59 anos & 1.047 & 5,4 & 1.184 & 5,6 & 1.378 & 6,2 & 15.640 & 6,9 & 1.095 & 1.216 & 1.350 \\
\hline 60-64 anos & 826 & 4,2 & 1.017 & 4,8 & 1.222 & 5,5 & 15.193 & 6,7 & 939 & 1.078 & 1.311 \\
\hline 65-69 anos & 648 & 3,3 & 788 & 3,7 & 1.042 & 4,7 & 14.758 & 6,5 & 728 & 919 & 1.274 \\
\hline 70-74 anos & 454 & 2,3 & 559 & 2,6 & 847 & 3,8 & 12.169 & 5,4 & 517 & 747 & 1.050 \\
\hline 75 anos ou mais & 666 & 3,0 & 694 & 3,0 & 1.103 & 5,0 & 24.337 & 10,8 & 641 & 973 & 2.100 \\
\hline Total & 19.535 & 100,0 & 21.138 & 100,0 & 22.143 & 100,0 & 226.348 & 100,0 & 19.535 & 19.535 & 19.535 \\
\hline
\end{tabular}

Fonte: Microdados da Pesquisa OD 2007; Projeção Demográfica estimada pela Fundação Seade (2012); Projeção Demográfica estimada pelo IBGE (2013). 
A Tabela 2 apresenta o número de viagens no transporte público que se esperaria observar na RMSP em 2007, caso ela tivesse a mesma estrutura etária estimada para 2020, 2030 e 2050. Como os IMEs são menores nas idades mais avançadas, as mudanças demográficas tendem a reduzir o total de viagens em 1,7\% (2020), 4,8\% (2030) e 9,5\% (2050) em relação a 2007.

TABELA 2

Estimativas do número de viagens realizadas no transporte público (1) antes e após padronização direta, segundo faixas etárias

Região Metropolitana de São Paulo - 2007-2050

\begin{tabular}{|c|c|c|c|c|c|c|c|c|c|}
\hline \multirow{3}{*}{ Faixas etárias } & \multirow{2}{*}{\multicolumn{2}{|c|}{$\begin{array}{c}\text { № de viagens em } \\
2007\end{array}$}} & \multirow{3}{*}{$\begin{array}{c}\text { Índice de } \\
\text { mobilidade } \\
2007\end{array}$} & \multicolumn{6}{|c|}{ № de viagens estimadas com estrutura etária } \\
\hline & & & & \multicolumn{2}{|c|}{2020} & \multicolumn{2}{|c|}{2030} & \multicolumn{2}{|c|}{2050} \\
\hline & Em mil & $\%$ & & Em mil & $\%$ & Em mil & $\%$ & Em mil & $\%$ \\
\hline $0-4$ anos & 80 & 0,7 & 0,1 & 97,5 & 0,8 & 81,5 & 0,7 & 64,2 & 0,6 \\
\hline $5-9$ anos & 116 & 1,0 & 0,1 & 120,6 & 1,0 & 103,5 & 0,9 & 81,8 & 0,8 \\
\hline 10-14 anos & 340 & 2,9 & 0,2 & 270,9 & 2,3 & 282,9 & 2,5 & 223,8 & 2,1 \\
\hline 15-19 anos & 1.282 & 10,8 & 0,8 & $1.051,4$ & 9,0 & $1.054,7$ & 9,3 & 828,7 & 7,7 \\
\hline 20-24 anos & 1.880 & 15,8 & 1,1 & $1.697,9$ & 14,5 & $1.298,2$ & 11,5 & $1.162,0$ & 10,8 \\
\hline 25-29 anos & 1.632 & 13,7 & 0,9 & $1.411,6$ & 12,1 & $1.224,8$ & 10,8 & $1.042,7$ & 9,7 \\
\hline 30-34 anos & 1.327 & 11,2 & 0,9 & $1.403,4$ & 12,0 & $1.293,6$ & 11,4 & $1.012,6$ & 9,4 \\
\hline 35-39 anos & 1.102 & 9,3 & 0,8 & $1.295,1$ & 11,1 & $1.095,1$ & 9,7 & 964,6 & 9,0 \\
\hline 40-44 anos & 1.014 & 8,5 & 0,7 & $1.113,9$ & 9,5 & $1.081,2$ & 9,5 & 949,5 & 8,8 \\
\hline 45-49 anos & 831 & 7,0 & 0,6 & 812,5 & 6,9 & 910,5 & 8,0 & 830,8 & 7,7 \\
\hline 50-54 anos & 720 & 6,1 & 0,6 & 710,8 & 6,1 & 805,7 & 7,1 & 797,7 & 7,4 \\
\hline 55-59 anos & 550 & 4,6 & 0,5 & 575,3 & 4,9 & 639,1 & 5,6 & 709,5 & 6,6 \\
\hline 60-64 anos & 376 & 3,2 & 0,5 & 427,4 & 3,7 & 490,5 & 4,3 & 596,6 & 5,5 \\
\hline 65-69 anos & 318 & 2,7 & 0,5 & 357,9 & 3,1 & 451,9 & 4,0 & 626,2 & 5,8 \\
\hline 70-74 anos & 180 & 1,5 & 0,4 & 204,7 & 1,8 & 296,1 & 2,6 & 416,3 & 3,9 \\
\hline 75 anos ou mais & 146 & 1,2 & 0,2 & 140,9 & 1,2 & 213,9 & 1,9 & 461,9 & 4,3 \\
\hline Total & 11.896 & 100,0 & 0,6 & 11.692 & 100,0 & 11.323 & 100,0 & 10.769 & 100,0 \\
\hline
\end{tabular}

Fonte: Microdados da Pesquisa OD 2007; Projeção Demográfica estimada pela Fundação Seade (2012); Projeção Demográfica estimada pelo IBGE (2013).

(1) Inclui metrô, trem, ônibus, lotação, micro-ônibus e vans.

Destaca-se ainda que há evidente mudança na composição das viagens, o que pode ser mais claramente visualizado no Gráfico 4. Pelas estimativas, a porcentagem de crianças entre 5 e 14 anos - consideradas estudantes que pagam meia tarifa - cairia levemente, de $3,8 \%$ em 2007 para $2,8 \%$ em 2050. Por outro lado, a proporção de passageiros pagantes diminuiria de $90 \%$ em 2007 para $87,4 \%$ em 2030 e $82,6 \%$ em 2050 , enquanto a participação no total de viagens dos passageiros com gratuidade completa (crianças com menos de cinco anos e idosos) aumentaria de 6,1\% em 2007 para 9,2\% em 2030 e 14,6\% no cenário de 2050.

Assim, a redução relativa do número de passageiros jovens que recebem alguma gratuidade seria pequena demais para compensar o decréscimo da população pagante e o aumento de passageiros idosos não pagantes. Embora esses resultados possam sofrer alguma alteração devido a mudanças no nível educacional da região metropolitana nos próximos anos, essas estimativas resultam, em larga medida, do fato de que a RMSP já se encontra no estágio de transição demográfica posterior ao seu bônus demográfico. 
Segundo estimativas da Fundação Seade (2012), a população da região metropolitana na faixa de idade ativa (15 a 59 anos de idade) e que possui maior participação nas viagens no transporte público já estaria em trajetória de declino, após ter alcançado seu ápice em meados de 2010.

\section{GRÁFICO 4}

Estimativas do número de viagens realizadas no transporte público (1) antes e após padronização direta, segundo faixas etárias

Região Metropolitana de São Paulo - 2007-2050

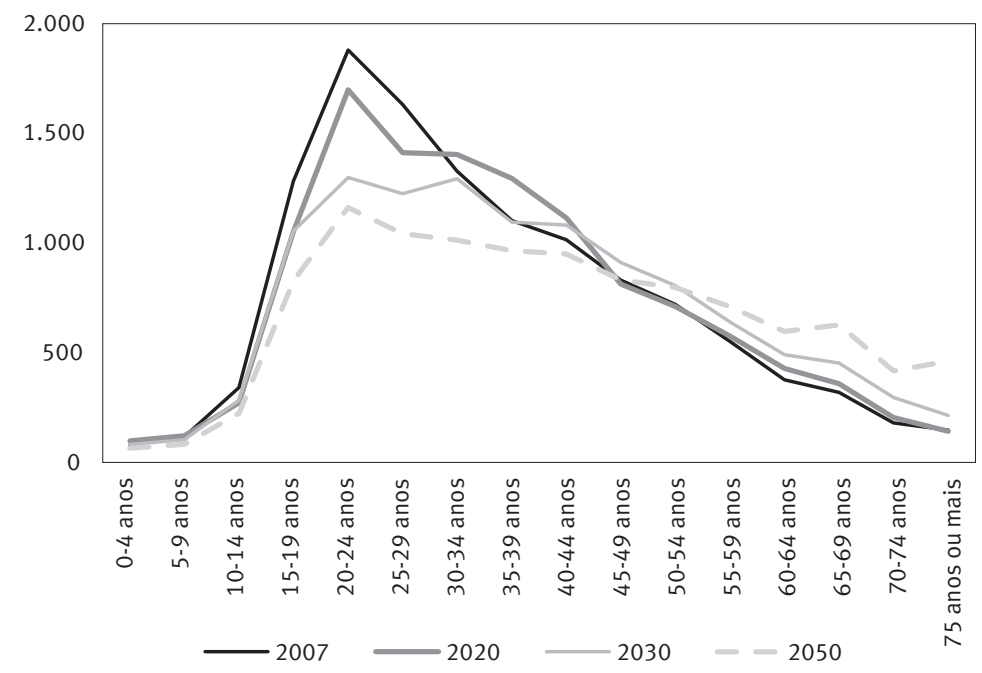

Fonte: Microdados da Pesquisa OD 2007; Projeção Demográfica estimada pela Fundação Seade (2012); Projeção Demográfica estimada pelo IBGE (2013).

(1) Inclui metrô, trem, ônibus, lotação, micro-ônibus e vans.

A Tabela 3 traduz os resultados anteriores em termos de viagens pagantes equivalentes e apresenta os impactos sobre o valor das tarifas cobradas. No cômputo final, observa-se que as viagens pagantes equivalentes, que representavam $92 \%$ do total de viagens em 2007, cairiam para 89,1\% em 2030 e $84 \%$ em 2050. Mantido o mecanismo de subsídio cruzado para financiar as gratuidades no transporte público, essa mudança da composição de passageiros pagantes e não pagantes acarretaria um sobrepreço do valor da tarifa cobrada. Em 2007, cada pessoa que fazia uma viagem pagando o valor da tarifa integral estava pagando um sobrepreço de $8,7 \%$ do custo da tarifa para financiar os benefícios tarifários concedidos a crianças, estudantes e idosos. Com a tendência de envelhecimento do perfil etário das viagens até 2020, 2030 e 2050, esse sobrepreço alcançaria 9,3\%, $12,3 \%$ e $19 \%$, respectivamente.

Os resultados apontam ainda que, mesmo mantendo-se o tamanho total da população constante, o envelhecimento populacional já seria suficiente para provocar uma redução futura no total de viagens na comparação com 2007. Essa redução do número de viagens, por si só, resultaria em aumento de $2 \%$ do custo médio por viagem até 2020 , de $5 \%$ até 2030 e de $10 \%$ até 2050 . 
TABELA 3

Estimativas das viagens pagantes e gratuitas equivalentes realizadas no transporte público (1) e indicadores, por anos de padronização da estrutura etária Região Metropolitana de São Paulo e Brasil - 2007-2050

\begin{tabular}{lrrrc}
\hline Viagens e indicadores & 2007 & RMSP 2020 & RMSP 2030 & Brasil 2050 \\
\hline Viagens pagantes equivalentes (A) (\%) & 92,0 & 91,5 & 89,1 & 84,0 \\
Viagens gratuitas equivalentes (B) (\%) & 8,0 & 8,5 & 10,9 & 16,0 \\
Sobrepreço em função de benefícios cruzados (B/A) (\%) & 8,7 & 9,3 & 12,3 & 19,0 \\
Total de viagens (C) & 11.896 & 11.692 & 11.323 & 10.769 \\
Custo total do sistema (D) & 11.896 & 11.896 & 11.896 & 11.896 \\
Custo médio da viagem (D/C) (\%) & 100,0 & 101,7 & 105,1 & 110,5 \\
Tarifa de equilíbrio (pagante equivalente) (R\$) & 1,087 & 1,11 & 1,18 & 1,31 \\
Encarecimento da tarifa de equilíbrio - base 2007 (\%) & 0,0 & 2,3 & 8,5 & 21,0 \\
\hline
\end{tabular}

Fonte: Microdados da Pesquisa OD 2007; Projeção Demográfica estimada pela Fundação Seade (2012); Projeção Demográfica estimada pelo IBGE (2013).

(1) Inclui metrô, trem, ônibus, lotação, micro-ônibus e vans.

Mantendo-se os subsídios cruzados e o nível de oferta dos serviços de transporte público, essa redução do total de viagens, combinada ao aumento da proporção de viagens não pagantes, tenderia a acarretar aumento no custo médio da viagem, que seria absorvido com um encarecimento da tarifa de equilíbrio. Para manter o equilíbrio do sistema, a tarifa cobrada ficaria mais cara em cerca de $8,5 \%$ e $21 \%$, respectivamente, nas projeções para 2030 e 2050 , em relação ao preço base de 2007.

\section{Considerações finais}

0 aumento das tarifas do transporte público nas cidades brasileiras tem ganhado crescente atenção por parte da opinião pública e de estudiosos nos últimos anos (NTU, 2005; BRASIL, 2006; CARVALHO; PEREIRA, 2012; CARVALHO et al., 2013). 0 sistema de financiamento das gratuidades concedidas a determinados segmentos de passageiros (como idosos e estudantes) tem um papel central nessa discussão, uma vez que a concessão desses benefícios impacta o preço final da tarifa cobrada de todos passageiros.

Com base nas projeções populacionais para 2020, 2030 e 2050, o presente trabalho usou como estudo de caso a Região Metropolitana de São Paulo para analisar os possíveis impactos que as transformações demográficas em curso na região poderão exercer sobre o valor da tarifa cobrada no sistema de transporte público. Os resultados indicam que, no curto prazo, o envelhecimento populacional projetado para a RMSP até 2020 teria um efeito relativamente modesto sobre o total de viagens realizadas no transporte público e sua composição etária. Isso parece coerente com a tendência demográfica geral da região, que ainda deverá observar, até 2020, uma quase estabilidade de sua população em idade ativa (15 a 64 anos). No médio e longo prazos, contudo, o crescimento previsto na porcentagem de passageiros com gratuidades deverá pressionar um aumento no valor 
das tarifas de cerca de $8,5 \%$ até 2030 e $21 \%$ até 2050 , caso seja mantido o mecanismo de subsídios cruzados para custear as gratuidades.

É importante ressaltar que esses valores são resultados estáticos simulando-se transformações demográficas abruptas. Não obstante, tanto as mudanças demográficas quanto os ajustes no sistema de transporte público ocorreriam gradualmente e seguindo a lógica de um sistema dinâmico. Nesse sentido, tais resultados não devem ser interpretados com um caráter de previsão determinística, até porque é sabido que projeções populacionais possuem naturalmente um componente de incerteza. Não se pode esperar que elas prevejam o futuro acuradamente. As dificuldades crescem quanto menor e mais aberta for a população projetada, que é o caso da Região Metropolitana de São Paulo. Neste caso, às dificuldades de prever o futuro da fecundidade, que já atingiu níveis abaixo de reposição, somam-se as dificuldades de se projetar migrações. A fecundidade é uma determinante importante do crescimento populacional e, principalmente, da estrutura etária. Das três variáveis demográficas básicas, a migração é a de mais difícil previsão, pois é a mais afetada pelas mudanças socioeconômicas. Ela também afeta a distribuição etária, pois os fluxos são concentrados nas idades produtivas.

No entanto, as simulações aqui apresentadas são úteis na medida em que apontam para uma tendência preocupante de aumento da pressão demográfica para a redução do número de viagens no transporte público e de crescimento do sobrepreço que as gratuidades exercerão sobre o valor da tarifa integral.

Dadas as atuais perspectivas de envelhecimento demográfico no país, a manutenção de um modelo de financiamento das gratuidades baseado no sistema de subsídios cruzados tende a agravar algumas distorções na tarifação desses serviços e a contribuir para o seu encarecimento. Esse problema poderia ser evitado, por exemplo, com alternativas de financiamento em que o subsídio a essas gratuidades é pago diretamente pela autoridade pública às empresas de transporte, segundo controle de bilhetagem eletrônica, a exemplo da experiência inglesa (METZ, 2003). Uma rediscussão do modelo atual poderá se beneficiar de estudos futuros que comparem os modelos de financiamento utilizados em outros municípios brasileiros e no exterior para custear tais benefícios tarifários, permitindo a realização de novas simulações incorporando modelos alternativos de financiamento.

Novos estudos também seriam necessários para simular cenários com diferentes alterações no padrão dos índices de mobilidade, o que poderia se valer de comparações internacionais e dos dados históricos das pesquisas OD de São Paulo, mas que não estão publicamente disponíveis. A replicação deste estudo para outras aglomerações urbanas no Brasil também parece promissora, uma vez que as tarifas de transporte público deverão ser impactadas com diferentes intensidades, a depender das legislações específicas de cada município e dos seus diferentes ritmos de envelhecimento populacional observados ao longo no território nacional (POTTER et al., 2010). Mas não se pode deixar de levar em conta que o objetivo da gratuidade é o de aumentar a integração social do idoso, evitando, assim, o seu isolamento e os males dele advindo, como a depressão. 
Para além da questão do financiamento do transporte público, o envelhecimento deverá colocar uma série de outros desafios às áreas como serviços de saúde e previdência social. No caso da mobilidade urbana, em particular, há uma vasta área de estudo ainda pouco explorada acerca dos padrões de deslocamento cotidiano da população idosa no Brasil e o que esses padrões revelam em termos de necessidades especiais de locomoção e dos desafios de inserção social desse grupo na mobilidade cotidiana das cidades. Ter uma melhor compreensão das características dessa demanda por transporte urbano será cada vez mais importante no país, devido ao crescimento desse perfil de usuários nas próximas décadas, o que demandará maior ação tanto das empresas prestadoras de serviço quanto por parte de autoridades públicas na elaboração de suas políticas de acessibilidade e de urbanização.

\section{Referências}

ANTP. Gratuidade nos transportes. Revista dos Transportes Públicos, ano 27/28, 2005.

BERENSTEIN, C. K.; WAJNMAN, S. Efeitos da estrutura etária nos gastos com internação no Sistema Único de Saúde: uma análise de decomposição para duas áreas metropolitanas brasileiras. Cadernos de Saúde Pública, v. 24, n. 10, p. 2301-2313, 2008.

BRASIL. Estatuto do Idoso. Lei n. 10.741/2003. Brasília, 2003.

. Congresso. Senado. Constituição da República Federativa do Brasil de 1988. Brasília: Senado Federal/Subsecretaria de Edições Técnicas, 2008.

CAMARANO, A. A. (Org.). Os novos idosos brasileiros: muito além dos 60? Rio de Janeiro: Ipea, 2004.

CAMARANO, A. A.; KANSO, S. Aspectos socioeconômicos do envelhecimento populacional. In: FREITAS, E. V. de; PY, L. A. O.; CANÇADO, F. A. X.; DOLL, J.; GORZONI, M. L. (Orgs.). Tratado de geriatria e gerontologia. 3. ed. Rio de Janeiro: Guanabara Koogan, 2011, v. 0, p. 1601-1613.

CAMARANO, A. A.; PASINATO, M. T. O envelhecimento populacional na agenda das políticas públicas. In: CAMARANO, A. A. (Org.). Os novos idosos brasileiros: muito além dos 60 ? Rio de Janeiro: Ipea, 2004, p. 256-292.

CARVALHO, C. H. R. de et al. Tarifação e financiamento do transporte público urbano. Nota Técnica n. 2. Brasília: Ipea, 2013.

CARVALHO, C. H. R. de; PEREIRA, R. H. M. Efeitos da variação da tarifa e da renda da população sobre a demanda de transporte público coletivo urbano no Brasil. Transportes, v. 20, p. 31-40, 2012.

CARVALHO, J. A. M.; SAWYER, D. O.; RODRIGUES, R. N. Introdução a alguns conceitos básicos e medidas em demografia. 2. ed. rev. São Paulo: Abep, 1998.

FUNDAÇÃO SEADE - Sistema Estadual de Análise de Dados. Sistema Seade de Projeções Populacionais. Disponível em: 〈http://www.seade.gov.br/produtos/projpop/〉. Acesso em: dez. 2012.

GOMIDE, A. de A. (Org.). Regulação econômica e organização dos serviços de transporte público urbano em cidades brasileiras: estudos de caso. Relatório final. Brasília: Ipea, Ministério das Cidades, 2004. 
Transporte urbano e inclusão social: elementos para políticas públicas. Brasília: Ipea, 2003 (Texto para discussão, n. 960).

IBGE - Instituto Brasileiro de Geografia e Estatística. Projeção da população do Brasil por sexo e idade para o período 2000-2060. Projeção da população das Unidades da Federação por sexo e idade para o período 2000-2030. Rio de Janeiro: IBGE, 2013. Disponível em: 〈http:// www.ibge.gov.br/home/estatistica/populacao/projecao_da_populacao/2013/default.shtm . Acesso em: set. 2013.

LIMA, I. M. O. Transporte urbano de passageiros: a tarifa como fonte de recursos. Brasília: Ipea, 1992 (Texto para discussão, n. 273).

MARANDOLA JR., E.; HOGAN, D. J. Ciclo vital e mobilidade na estruturação dos espaços de vida nas regiões metropolitanas de Campinas e da Baixada Santista, Brasil. In: III CONGRESSO DA ASOCIACIÓN LATIONOAMERICANA DE POBLACIÓN. Anais... Cordoba: Alap, 2008.

MERCADO, R.; PÁEZ, A.; SCOTT, D. M.; NEWBOLD, K. B.; KANAROGLOU, P. Transport policy in aging societies: an international comparison and implications for Canada. Open Transportation Journal, v. 1, n. 1, p. 1-13, 2007.

METRÔ - Companhia do Metropolitano de São Paulo. Pesquisa Origem e Destino 2007 da Região Metropolitana de São Paulo - microdados da Pesquisa Domiciliar. São Paulo, dezembro de 2008.

METZ, D. Transport policy for an ageing population. Transport Reviews, v. 23, n. 4, p. 375-386, 2003.

OLIVEIRA, A. G.; SOUZA, M. L. R.; KARNOKOWSKI, M. G. O.; TACO, P. W. G.; MOTTA, R. A. Direitos dos idosos relacionados à sua mobilidade. Revista dos Transportes Públicos, v. 130, p. 85-100, 2012.

PAEZ, A.; SCOTT, D.; POTOGLOU, D.; KANAROGLOU, P.; NEWBOLD, K. B. Elderly mobility: demographic and spatial analysis of trip making in the Hamilton CMA, Canada. Urban Studies, v. 44, n. 1, p. 123-146, 2007.

PÉREZ, E. R.; WAJNMAN, S.; OLIVEIRA, A. Análise dos determinantes da participação no mercado de trabalho dos idosos em São Paulo. Revista Brasileira de Estudos de População, v. 23, n. 2, p. 269-286, 2006.

POTTER, J.; SCHMERTMANN, C.; ASSUNÇÃO, R.; CAVENAGHI, S. Mapping the timing, pace, and scale of fertility transition in Brazil. Population and Development Review, v. 36, n. 2, 2010.

PRESTON, S. H.; HEUVELINE, P.; GUILLOT, M. Demography: measuring and modeling population processes. Oxford, UK: Blackwell, 2001.

ROBERTS, P. W.; BABINARD, J. Transport strategy to improve accessibility in developing countries. In: 10th INTERNATIONAL CONFERENCE ON MOBILITY AND TRANSPORT FOR ELDERLY AND DISABLED PEOPLE. Anais... Hamamatsu, Japão, 2004. Disponível em: 〈http://trid.trb.org/ view.aspx?id=891027>. Acesso em: 23 abr. 2012.

SANT'ANNA, R. M. de; BRAGA, M. G. de C.; SANTOS, M. P. de S. Segurança no trânsito para os motoristas idosos: desafios e perspectivas. Textos sobre Envelhecimento, v. 7, n. 1, p. 7-8, 2004.

SANT'ANNA, R. M. de; CAMARA, P.; BRAGA, M. G. de C. Mobilidade na terceira idade: como planejar o futuro. Textos sobre Envelhecimento, v. 6, n. 2, 2003.

SCHWANEN T.; PÁEZ, A. The mobility of older people - an introduction. Journal of Transport Geography, v. 18, n. 5, p. 591-595, 2010.

TURRA, C. M.; QUEIROZ, B. L.; RIOS-NETO, E. L. Idiosyncrasies of intergenerational transfers in Brazil. In: LEE, R. D.; MASON, A. (Eds.). Population aging and the generational economy: a global perspective. Cheltenham: Edward Elgar, 2011. p. 394. 
VASCONCELLOS, E. A. Transporte, espaço e equidade: análise das políticas públicas. 3. ed. São Paulo: Annnablume, 2001.

WASFI, R.; LEVINSON, D.; EL-GENEIDY, A. Measuring the transportation needs of seniors. Journal of Transport Literature, v. 6, n. 2, p. 8-32, out. 2012.

WONG, L. L. R.; CARVALHO, J. A. O rápido processo de envelhecimento populacional do Brasil: sérios desafios para as políticas públicas. Revista Brasileira de Estudos Populacionais, v. 23, n. 1, p. 5-26, 2006.

\title{
Sobre os autores
}

Rafael Henrique Moraes Pereira é doutorando em Geografia na Universidade de Oxford e mestre em Demografia pela Universidade Estadual de Campinas - Unicamp.

Carlos Henrique Ribeiro de Carvalho é mestre em engenharia civil pelo Instituto Alberto Luiz Coimbra de Pós-Graduação e Pesquisa em Engenharia - Coppe, da Universidade Federal do Rio de Janeiro - UFRJ.

Pedro Herculano G. Ferreira de Souza é doutorando em Sociologia pela Universidade de Brasília - UnB, visiting student researcher no Departamento de Economia da Universidade da Califórnia, Berkeley, USA e mestre em Sociologia pelo Instituto Universitário de Pesquisas do Rio de Janeiro - luperj.

Ana Amelia Camarano é demógrafa com doutorado na London School of Economics (LSE) e mestrado no Centro de Desenvolvimento e Planejamento Regional - Cedeplar, da Universidade Federal de Minas Gerais - UFMG.

\section{Endereço para correspondência}

\author{
Rafael Henrique Moraes Pereira \\ St Edmund \\ Queen's Lane \\ OX1 4AR \\ Oxford, UK
}

\begin{abstract}
Population aging, fare concessions on public transport and its effects on transport fares in São Paulo Metropolitan Area

In Brazil, students, children under four years of age and people aged 65 and over are entitled to partial or full concessions on urban travel in public transport systems. These discounts are not covered by public funding, but rather via cross-subsidization charged to the other service users who pay the full fare. In this study, the effects of population aging on public transport fares for the next four decades in the metropolitan region of São Paulo (MRSP), the largest metropolitan area in Brazil, are estimated. The analyses in this paper are based on data from the Pesquisa Origem-Destino (Origin-Destination Survey), carried out in 2007 in the MRSP, and on official population projections developed by IBGE (the Brazilian Institute of Geography and Statistics) and Fundação Seade (the Seade Foundation) for the years 2020, 2030 and 2050. Considering the different periods of population projection, the technique of direct standardization to simulate
\end{abstract}


expected changes in the composition of public transport trips was utilized, in terms of paying and non-paying passengers. The results indicate that, in the short term (2020), population aging expected to occur in the MRSP should have a modest effect on the total number and age composition of public transport trips in the region. However, if the current cross-subsidization mechanism is maintained, the expected growth in the percentage of non-paying passengers could result in an increase in fares by about $10 \%$ and $20 \%$ in the medium and long terms.

Keywords: Demographic aging. Public transport. Urban transport. Fare. Free transport. São Paulo Metropolitan Region.

\section{Resumen}

Envejecimiento de la población, gratuidad en el transporte público y sus efectos sobre las tarifas en la Región Metropolitana de São Paulo

En Brasil, los estudiantes, los niños menores de 4 años y las personas de 65 años o más tienen derecho a descuentos parciales o totales en los viajes urbanos en los sistemas de transporte público. Estos descuentos no son cubiertos por fondos públicos, sino por un subsidio cruzado cobrado a los demás usuarios de los servicios que pagan la tarifa completa. En este estudio, se estiman los efectos del envejecimiento de la población sobre el precio de los pasajes del transporte público en las próximas cuatro décadas en la Región Metropolitana de São Paulo (RMSP), la mayor región metropolitana del país. Los análisis se basan en los datos de la Encuesta de Origen-Destino realizada en 2007 en la RMSP y en las proyecciones demográficas elaboradas por el IBGE y por la Fundación SEADE para 2020, 2030 y 2050. Teniendo en cuenta los diferentes escenarios de proyección de la población, se utiliza la técnica de estandarización directa para simular los cambios esperados en la composición de los viajes del sistema de transporte en términos de pasajeros que pagan y que no lo hacen. Los resultados indican que, en el corto plazo (2020), el envejecimiento de la población estimado en la RMSP tendría un efecto modesto sobre el número total y la composición por edades de los viajes realizados en el transporte público de la región. En el mediano y el largo plazo, sin embargo, el aumento previsto de la proporción de pasajeros con el beneficio de la gratuidad podría causar un incremento del sobreprecio de la tarifa, con una elevación de su valor de entre el $10 \%$ y el $20 \%$, en caso de mantenerse el mecanismo de subsidio cruzado.

Palabras clave: Envejecimiento demográfico. Transporte público. Transporte urbano. Tarifa. Gratuidad. Región Metropolitana de São Paulo. 